Vol. 2 No. 2 Juli 2019

ISSN 2614-2775

e-ISSN 2621-8143
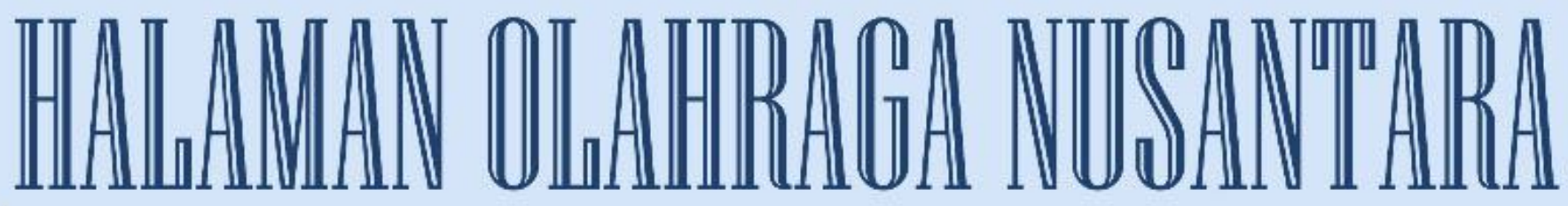

Surnal @lmu Xeolahragaan

Diterbitkan Oleh:

Program Studi Pendidikan Olahraga

Fakultas Keguruan dan Ilmu Pendidikan

Universitas PGRI Palembang

\begin{tabular}{|c|c|c|c|c|c|}
\hline Jurnal & Volume & Nomor & Halaman & Palembang & ISSN/e-ISSN \\
\hline IIalaman Oahrayg Ninsantarata & 2 & 2 & $97-197$ & 2019 & $\begin{array}{c}2614-2775 / \\
2621-8143\end{array}$ \\
\hline
\end{tabular}


Halaman Olahraga Nusantara (Jurnal Ilmu Keolahragaan)

P-ISSN 2614-2775

Volume 2, No. 2, Januari 2019

E-ISSN 2621-8143

\section{DAFTAR ISI}

Hasil Penelitian

Halaman

Penerapan Model Permainan Rounders Yang Dimodifikasi Terhadap Kemampuan Gerak Dasar Murid Sd Negeri Paccinongan Kabupaten Gowa

- Benny B, M.Rachmat Kasmad

Pelaksanaan Kegiatan Belajar Mengajar Pendidikan Jasmani di Sekolah Dasar Inklusi

- Bambang Gatot Sugiarto

Pengaruh Metode Latihan Terhadap Daya Tahan Fisik Siswa Ekstrakurikuler Sepak Bola Sma N 2 Tanjung Raja

- Mutiara Fajar.

Survei Minat Member Yang Mengikuti Fitness Pada Pusat Kebugaran Kota Palembang

- Hengki Kumbara.

Peningkatan Pengaruh Latihan Kelincahan Terhadap Kemampuan Menggiring Bola Pada Siswa Sma Negeri 3 Samarinda

- Ruslan, Nurjamal

Penerapan Permainan Dengnan Media Swiss Ball Untuk Meningkatkan Kelentukan Lower Back (Pada Mahasiswa Kop Aerobic Gymnastics Universitas Negeri Jakarta)

- M Dian Susanto, Sri Nuraini $141-153$

Patrol Multiguna Sebagai Alternatif Media Pembelajaran Tolak Peluru Di Smp Negeri 1 Sei Balai Kabupaten Batu Bara Tahun Ajaran 2017/2018

- Joko Priono $154-166$ 
Kecerdasan Gerak Dalam Pendidikan Jasmani

- Hilda Oktriyeni....................................................................... 167-176

Analisis Kesalahan Tendangan Atlet Pencak Silat Universitas PGRI Palembang

- Bayu Iswana............................................................................ 177-185

Pengaruh Metode Pembelajaran Dan Kriteria Layanan Bantuan:

Meningkatkan Gerak Dasar Lompat Jauh Gaya Jongkok Siswa Tunagrahita Ringan Pada Pembelajaran Penjasorkes SLB PKK Bandar Lampung

- Rachmi Marsheilla Aguss.............................................................. 186-197 


\title{
PATROL MULTIGUNA SEBAGAI ALTERNATIF MEDIA PEMBELAJARAN TOLAK PELURU DI SMP NEGERI 1 SEI BALAI KABUPATEN BATU BARA TAHUN AJARAN 2017/2018
}

\author{
Oleh: Joko Priono \\ (Dosen Universitas Pembinaan Masyarakat Indonesia Medan)
}

\begin{abstract}
Abstrak
Penelitian ini bertujuan menghasilkan sebuah alat/media modifikasi tolak peluru yang dapat digunakan untuk beberapa permainan tolak peluru, sehingga produk ini dapat dimanfaatkan sebagai alat pembelajaran di sekolah khususnya di SMPN 1 Sei Balai.Metode yang digunakan dalam penelitian ini adalah penelitian dan pengembangan $R \& D$ yang bertujuan menghasilkan produk berupa alat/media pembelajaran tolak peluru, namun sesunguhnya alat yang peneliti kembangkan dapat dijadikan media pembelajaran lompat jauh dan tiang lompat tinggi namun karena keterbatasan waktu maka disini peneliti hanya membahas alat untuk permainan tolak peluru. Dalam penelitian ini, data mengenai kualitas produk yang dihasilkan, dibantu menggunakan angket peneletian. Agar didapat kualitas alat/media yang berkualitas tinggi, maka dalam proses pembuatannya dilakukan beberapa tahapan, yaitu uji validasi kepada ahli alat, uji validasi kepada 2 orang ahli atletik, uji coba kepada siswa (pengguna) dalam kelompok kecil, uji coba kepada siswa pada kelompok besar.Hasil penelitian ini adalah sebuah patrol multiguna sebagai alternatif media pembelajaran tolak peluru dengan kualitas yang "Baik". Hal tersebut dibuktikan dengan diperolehnya hasil validasi ahli alat dengan rata-rata skor 4,80 yang termasuk dalam kategori "Sangat baik", diperolehnya validasi kedua ahli atletik yang memiliki skor yang sama yaitu rata-rata skor 4.60 yang termasuk dalam kategori "Sangat Baik" dan diperolehnya hasil uji coba pada siswa SMPN 1 Sei Balai dengan rerata skor 4.70 yang termasuk dalam kategori "Sangat Baik".
\end{abstract}

Kata Kunci: Patrol Multiguna, Alternatif, Media Pembelajaran, Tolak Peluru.

\section{MULTIPURPOSE PATROL AS AN ALTERNATIVE TO THE BULLET- DROP LEARNING MEDIA IN STATE JUNIOR HIGH SCHOOL 1 SEI BALAI BATU BARA DISTRICT IN THE ACADEMIC YEAR 2017/2018}

\begin{abstract}
This study aims to produce a bullet modification tool / media that can be used for a number of bullet games, so that this product can be used as a learning tool in schools especially at Sei Balai 1 Public Middle School. The method used in this research is research and development of $R \& D$ which aims to produce products in the form of tools / media for shooting bullets, but actually the tools that researchers develop can be used as learning media for long jumps and high jump poles but due to time constraints, here researchers only discuss tools for bullet game. In this study, data on the quality of the products produced, were
\end{abstract}


assisted using a research questionnaire. In order to obtain high quality quality tools / media, several stages are carried out in the manufacturing process, namely validation test to tool experts, validation test to 2 athletic experts, testing to students (users) in small groups, testing to students in groups big. The results of this study are a multipurpose patrol as an alternative to "Good" bullet-quality learning media. This is evidenced by obtaining the results of tool expert validation with an average score of 4.80 which is included in the "Very Good" category, obtained by validation of the two athletic experts who have the same score, namely the average score of 4.60 which is included in the "Very Good" category and obtained the results of trials on Sei Balai 1 Public Middle School students with a mean score of 4.70 which is included in the "Very Good" category.

Keywords: Multipurpose Patrol, Alternative, Learning Media, Refuse Bullets .

\section{A. PENDAHULUAN}

Perkembangan iptek semakin mendorong upaya-upaya pembaharuan dalam pemanfaatan hasil teknologi dalam proses belajar. Para guru dituntut untuk mampu menggunakan alat-alat yang dapat disediakan sekolah, dan tidak tertutup kemungkinan bahwa alat-alat tersebut sesuai dengan perkembangan dan tuntutan zaman. Atletik merupakan salah satu mata pelajaran pendidikan jasmani (penjas) yang wajib diberikan kepada siswa sekolah dasar, sekolah menengah pertama, dan sekolah menengah atas, sesuai dengan SK Mendikbud No. 0413/U/87.

Muncul pertanyaan, mengapa atletik merupakan suatu mata pelajaran yang wajib diberikan di sekolah-sekolah?. Mengapa tidak semua cabang olahraga wajib diberikan di sekolah-sekolah?. Jawabannya logis adalah: "atletik merupakan ibu dari sebagian besar cabang olahraga", dimana gerakan-gerakan yang ada dalam atletik seperti jalan, lari, lompat dan lempar dimiliki sebagian besar cabang olahraga.

Salah satu cabang olahraga Atletik adalah tolak peluru, tolak peluru ialah gerakan menolak suatu alat bundar dengan berat tertentu yang dilakukan dari bahu dengan satu tangan untuk mencapai jarak sejauh-jauhnya.Kita ketahui bahwa tolak peluru mulai diajarkan di sekolah-sekolah tingkat menengah sampai tingkat atas di seluruh Indonesia dan merupakan suatu pelajaran wajib bagi siswa-siswi. Namun pada kenyataannya masih banyak siswa-siswi yang kurang mengerti apadan bagaimana cara melakukan tolak peluru, siswa-siswi dalam pelajaran 
pendidikan jasmani lebih memilih pelajaran olahraga permainan seperti kasti, sepak bola, dan bola voli.

Hasil observasi yang peneliti lakukan di Sekolah SMP Negeri 1 Sei Balai Kabupaten Batu Bara pada tanggal 23 s/d 24 september 2017 ternyata masih banyak siswa yang kurang berminat dalam mengikuti pelajaran tolak peluru, disebabkan cara mengajar guru yangmanoton.Sarana dan prasarana yang ada di sekolah cukup memadai seperti terdapat lapangan Voli, lapangan rumput dengan luas kurang lebih 300 meter persegi, bak pasir lompat jauh walaupun tidak terawat, 5 buah bola kaki, 5 buah bola basket, 6 buah bola voli, 2 buah cakram, 23 buah peluru yang dimodifikasi, 10 buah bola berekor, dan 2 buah matras.

Masih banyak siswa dan siswi yang tidak antusias terhadap pelajaran tolak peluru dengan alasan yang tidak jelas khususnya siswa perempuan, sehingga hasil belajar tolak peluru mereka dari 32 siswa hanya 11 siswa saja yang mencapai KKM. Mengenai model pembelajaran yang diberikan kepada siswa-siswinya guru menyatakan hanya memberi model pembelajaran tolak peluru dengan cara menolak peluru sejauh-jauhnya dan menolak secara berpasangan. Menurut penulis cara guru memberikan pelajaran tolak peluru kurang menarik dan menyenagkan, sejatinya guru memberikan pelajaran tolak peluru dengan cara menolak sejauh-jauhnya dan menolak berpasangan tidaklah sepenuhnya salah namun alangkah baiknya apabila seorang guru dalam menyajikan pelajaran tolak peluru menggunakan beberapa variasi pembelajaran yang telah ditemukan oleh beberapa ahli, seperti salah satunya yaitu menolak peluru melewati rintangan tali dan lain sebagainya. Karena apabila guru dalam menyajikan pelajaran hanya menggunakan menolak berpasangan dan menolak sejauh-jauhnya maka hal ini tentu akan sangat membosankan karena sejatinya manusia adalah makhluk yang suka bermain, oleh karena itu akan menjadi nilai lebih dimata siswa apabila guru dalam menyajikan pelajaran tolak peluru menggunakan beberapa variasi yang telah ada dan tidak tertutup kemungkinan merancang media atau alat bantu yang dapat mempermudah pekerjaan guru dalam menyajikan beberapa variasi pembelajaran tolak peluru. 
Dari hasil wawancara yang peneliti lakukan terhadap 32 siswa-siswi SMP N 1 Sei Balai kelas VII-1 melalui angket maka didapati dari mereka bahwa mereka menyukai pelajaran penjas dalam bentuk permainan dan bosan dengan pelajaran tolak peluru. Ini juga salah satu alasan mengapa mereka kurang antusias dalam mengikuti pelajaran tolak peluru sehingga pada akhirnya hasil belajar tolak peluru mereka masih banyak yang tidak mencapai ketuntasan.

Hasil observasi dan wawancarapeneliti menyimpulkan pembelajaran tolak peluru di SMP N 1 Sei Balai guru pendidikan jasmanimemberikan pembelajaran tolak peluru dengan cara yang biasa dan terkesan membosankan tanpa ada variasi yang bagus serta modifikasi dengan sebuah sentuhan yang mengubah pembelajaran tersebut menjadi lebih baik dan dapat diterima dengan adanyainovasi media pembelajaran. Guru memberi petunjuk dari samping dengan komando dibarisan siswa untuk melakukan tolakan secara bersama kedepan dan melakukan tolakan dengan area segitiga bersama teman.Cara tersebut tidak salah akan tetapi bisa memberi gerakan yang lebih banyak menarik perhatian siswa, lebih baik bila seorang guru pendidikan jasmani melihat proses anak melalui beberapa tahapan tolakan, koordianasi kaki tangan, ataupun keseimbangan tubuhnya agar dapat membantu anak untuk mendapatkan teknik tolak peluru yang benar, dan tak ada salahnya pula apabila seorang guru merancang media atau alat bantu yang dapat menerapkan beberapa variasi yang inovatif pembelajaran tolak peluru, karena di dekat sekolah ada banyak kayu broti yang dapat dimanfaatkan sehingga nantinya media itu dapat memudahkan guru dalam menyajikan pembelajaran tolak peluru.

Dari hasil uraianini maka peneliti tertarik sekali untuk membuat suatu media pembelajaran tolak peluru yang menarik perhatian siswa-siswi dalam mengikuti pelajaran pendidikan jasmanikhusus pada materi tolak peluru agar dapat meningkatkan perbaikan hasil belajar siswa.Alat ini diciptakan agar dapat memudahkan guru dalam memberikan pembelajaran tolak peluru, bagi siswa juga bermanfaat dalam mendapatkan pembelajaran, kebermanfaatan media ini bagi siswa ialah dapat diterapkan berbagai variasi pembelajran tolak peluru yang ada. Alat tersebut berbentuk seperti setengah lingkaran yang mempunyai tinggi 2 
meter ketinggian juga dapat disesuaikan, lebar juga dapat disesuaikan.Media ini terbuat dari kayu, triplek, tali, katrol dan baut sebagai pengikatnya. Untuk itu judul penelitian yang ditawarkan adalah: "Patrol Multiguna Sebagai Alternatif Media Pembelajaran Tolak PELURU di SMP Negeri 1 Sei Balai” Tahun Ajaran $2017 / 2018$.

\section{B. METODE PENELITIAN}

Metode yang digunakan dalam penelitian ini adalah penelitian pengembangan yang mencakup pengembangan produk, menguji keefektifan produk untuk mencapai tujuan yang diinginkan.Penelitian dan pengembangan yang peneliti lakukan merupakan penelititan yang bertujuan untuk menghasilkan produk yang berupa alat atau media pembelajaran yang multiguna, dikatakan multiguna karena berbagai macam variasi pembelajaran tolak peluru dapat diterapkan dimedia ini.

\section{Langkah-Langkah :}

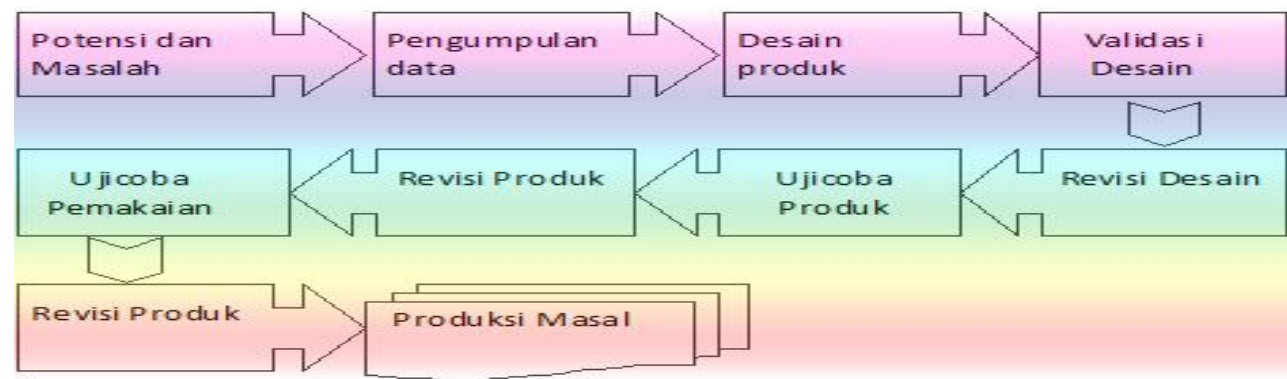




\section{Hasil dan Pembahasan}

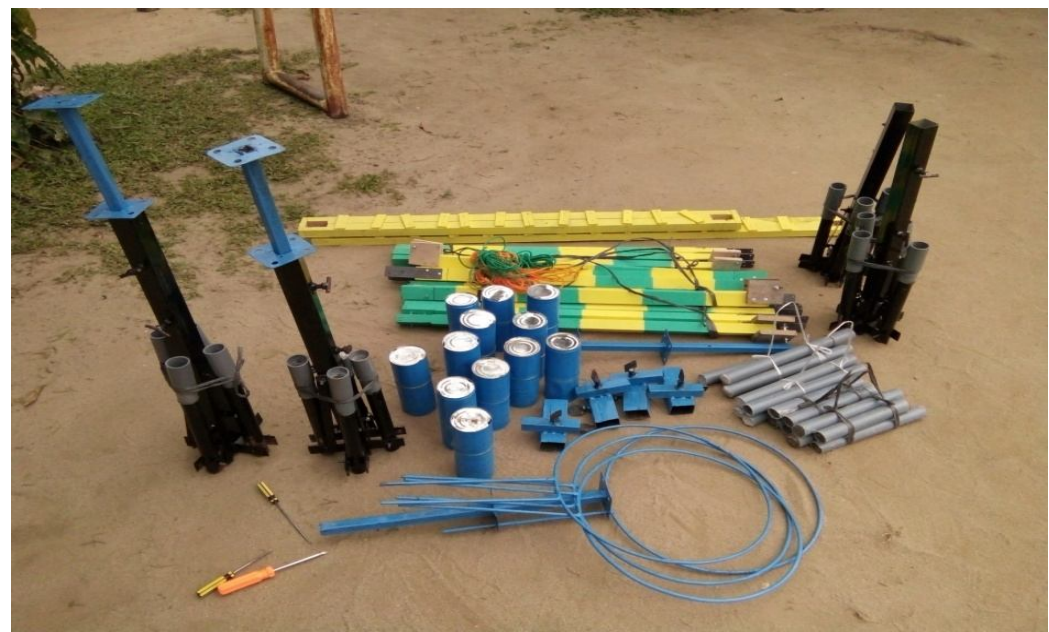

Gambar : Alat sebelum dirakit.

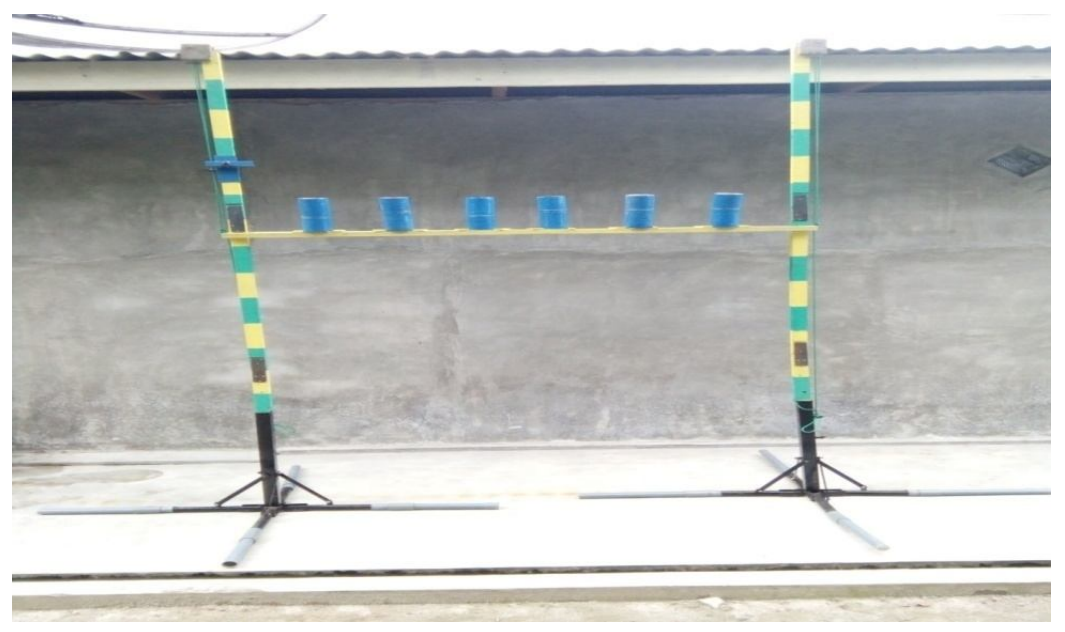

Gambar : Alat pembelajaran permainan benteng sesudah dirakit

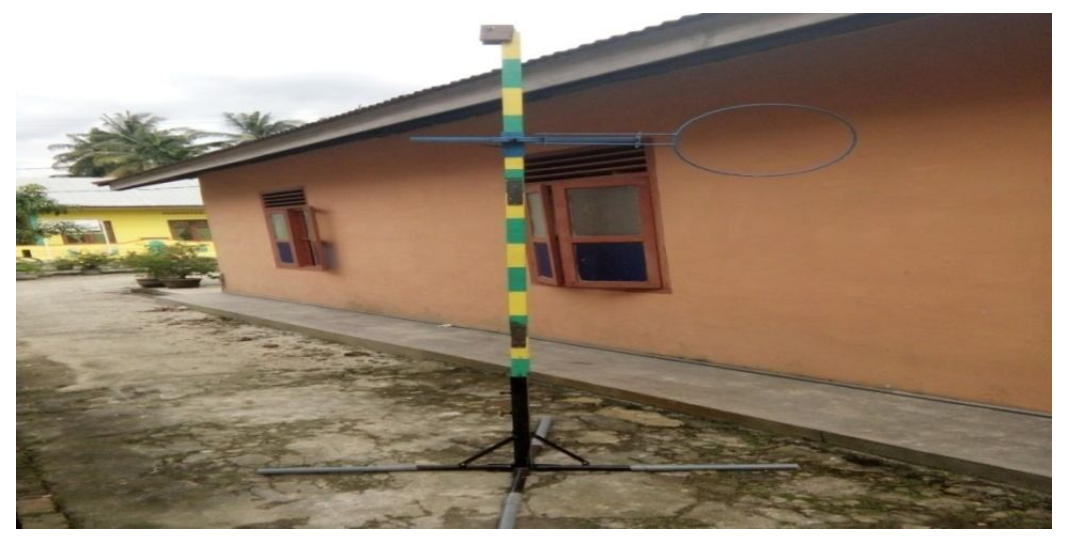

Gambar :Alat pembelajaran permainan ring basket setelah dirakit 


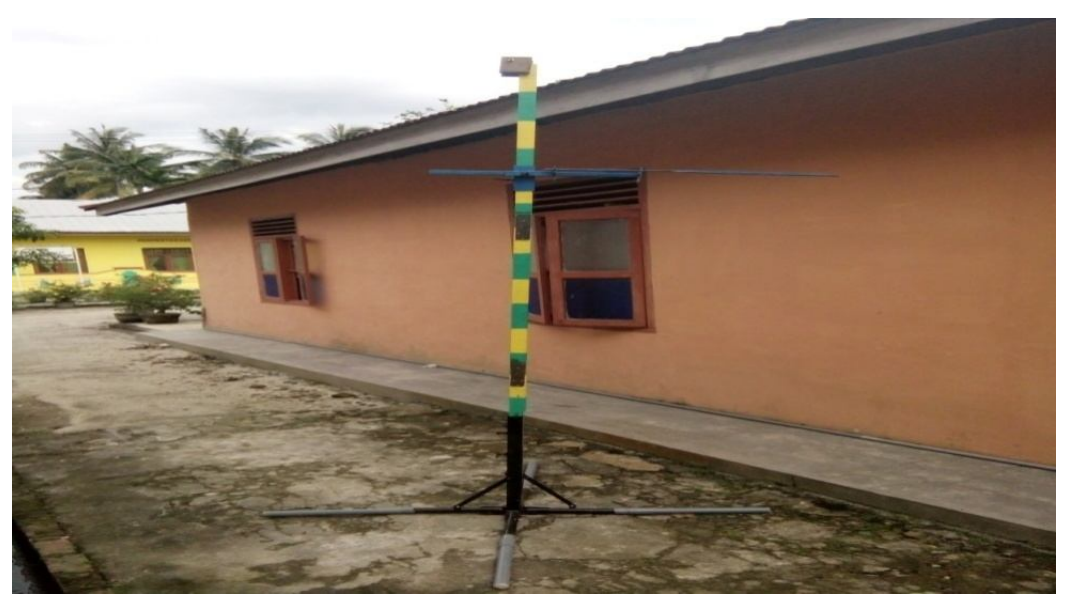

Gambar :Alat pembelajaran permainan ring basket sebelum dirakit

Data Validasi Ahli Alat

\begin{tabular}{|l|l|c|}
\hline No & \multicolumn{1}{|c|}{ Aspek yang dinilai } & Ahli alat \\
\hline 1 & $\begin{array}{l}\text { Besi dan bahan lainnya yang digunakan pada alat tahan dan } \\
\text { baik untuk digunakan }\end{array}$ & 5 \\
\hline 2 & Ukuran alat sudah sesuai dengan kebutuhan siswa disekolah & 4 \\
\hline 3 & Desain media simple dan mudah dipindah-pindahkan & 5 \\
\hline 4 & Alat sudah aman dan dapat digunakan & 5 \\
\hline 5 & $\begin{array}{l}\text { Patrol multiguna ini dapat dijadikan sebagai alternative media } \\
\text { pembelajaran tolak peluru }\end{array}$ & 5 \\
\hline & \multicolumn{2}{|c|}{24} \\
\hline
\end{tabular}

Data Validasi Ahli Atletik

\begin{tabular}{|l|l|l|l|}
\hline No & \multicolumn{1}{|c|}{ Aspek yang dinilai Ahli I } & \multicolumn{1}{|c|}{$\begin{array}{c}\text { Ahli } \\
\text { II }\end{array}$} \\
\hline 1 & $\begin{array}{l}\text { Variasi pembelajaran tolak peluru dapat diterapkan } \\
\text { untuk siswa Sekolah Menengah Pertama }\end{array}$ & 5 & 5 \\
\hline 2 & Ketinggian alat & 5 & 5 \\
\hline 3 & Alat/media sesuai dengan siswa dapat diterapkan pada media ini dapat & 5 & 5 \\
\hline 4 & Variasi yang dap & 5 \\
\hline
\end{tabular}




\begin{tabular}{|l|l|l|l|}
\hline & $\begin{array}{l}\text { meningkatkan antusias siswa dalam pembelajaran tolak } \\
\text { peluru }\end{array}$ & \\
\hline 5 & $\begin{array}{l}\text { Pembelajaran lebih efektif dan efisien dengan alat/media } \\
\text { ini }\end{array}$ & 4 & 4 \\
\hline 6 & $\begin{array}{l}\text { Alat/media ini dapat membantu memenuhi kebutuhan } \\
\text { alat/media pembelajaran atletik di sekolah }\end{array}$ & 5 & 5 \\
\hline 7 & $\begin{array}{l}\text { materi variasi pembelajaran dalam manual book sudah } \\
\text { jelas }\end{array}$ & 4 & 4 \\
\hline 8 & $\begin{array}{l}\text { Alat dapat dibongkar pasang sehingga mudah untuk } \\
\text { digunakan oleh guru dan siswa }\end{array}$ & 4 & 4 \\
\hline 9 & $\begin{array}{l}\text { Harga alat terjangkau sehingga sekolah dapat } \\
\text { memenuhinya }\end{array}$ & 5 & 5 \\
\hline 10 & Alat tahan pakai dan tidak ringkih & 4 & 4 \\
\hline Jumlah Skor & 46 & 46 \\
\hline Rata-rata skor & 4,6 & 4,6 \\
\hline
\end{tabular}

Hasil Uji Coba Kelompok Kecil

\begin{tabular}{|l|l|l|l|l|}
\hline NO & Pertanyaan & Jumlah skor & Rata-rata & Kategori \\
\hline 1 & Alat ini menyenangkan & 40 & 4 & setuju \\
\hline 2 & Alat mudah digunakan & 40 & 4 & Setuju \\
\hline 3 & Bentuk alat bagus & 30 & 3 & Ragu-ragu \\
\hline 4 & $\begin{array}{l}\text { Alat tahan pakai dan tidak } \\
\text { roboh ketika terkena peluruh }\end{array}$ & 46 & 4,6 & Sangat setuju \\
\hline 5 & $\begin{array}{l}\text { Menggunakan alat ini disetiap } \\
\text { pembelajaran tolak peluru }\end{array}$ & 43 & 4,3 & Sangat setuju \\
\hline
\end{tabular}

\section{Revisi Produk}

Dari penjelasan tabel diatas terdapat kekurangan pada alat yaitu kemudahan alat saat digunakan, dan bentuk alat yang kurang menarik atau kurang bagus, dari kekurangan-kekurangan alat diatas dapat dijelaskan sebagai berikut:

1. kemudahan alat dalam penggunaan 
a. Dalam pemasangan/perakitan alat masih banyak kendala baik dalam perakitan alat sebagai permainan tolak peluru dalam lingkaran dan tolak peluru ring basket.

b. Dalam permainan peluru kaleng masih sulit karena ketika peluru mengenai tiang kaleng sudah berjatuhan, hal ini merepotkan karena harus menyusun kembali susunan kaleng tiap kali tolakan yang melenceng ke tiang, hal yang perlu diperhatikan ialah kedudukan kaleng agar diperkokoh.

2. bentuk alat

Bentuk alat bagi siswa ialah warna alat perlu diperbaharui.Dari kekurangan-kekurangan diatas selanjutnya peneliti melakukan diskusi kepada ahli alat untuk perbaikan alat yang lebih bagus lagi.Dalam forum diskusi peneliti dengan ahli alat, peneliti membawa hasil dari masukan-masukan dari para siswa. Masukan yang diberikan oleh ahli atletik didapat perubahan bentuk alat dari permainan tolak peluru dalam lingkaran tolak peluru ring basket yang sebelumnya menggunakan 2 tiang kini hanya menggunakan 1 tiang, lingkaran yang sebelumnya hannya menggunakan selang air kini berubah menggunakan besi lingkaran untuk memudahkan pemasangan dan kekokohan saat terkena peluru, bagitu juga pewarnaan ialah atas dasar dari saran ahli alat. Setelah semua desain alat dan warna selesai maka selanjutnya peneliti melakukan perubahan pada alat dan selanjutnya peneliti mencobanya kembali kepada uji coba kelompok besar.

\section{Uji Coba Kelompok Besar}

\begin{tabular}{|l|l|c|c|l|}
\hline NO & Pertanyaan & Jumlah skor & Rata-rata & Kategori \\
\hline 1 & Alat ini menyenangkan & 164 & 4.8 & $\begin{array}{l}\text { Sangat } \\
\text { Setuju }\end{array}$ \\
\hline 2 & Alat mudah digunakan & & & \\
\hline 3 & Bentuk alat bagus & 168 & 4.9 & $\begin{array}{c}\text { Sangat } \\
\text { Setuju }\end{array}$ \\
& & & & $\begin{array}{c}\text { Sangat } \\
\text { Setuju }\end{array}$ \\
\hline
\end{tabular}




\begin{tabular}{|l|l|c|c|c|}
\hline 4 & $\begin{array}{l}\text { Alat tahan pakai dan tidak } \\
\text { roboh ketika terkena peluru }\end{array}$ & 164 & 4.8 & $\begin{array}{l}\text { Sangat } \\
\text { Setuju }\end{array}$ \\
\hline 5 & $\begin{array}{l}\text { Menggunakan alat ini disetiap } \\
\text { pembelajaran tolak peluru }\end{array}$ & 162 & 4.7 & $\begin{array}{l}\text { Sangat } \\
\text { Setuju }\end{array}$ \\
\hline
\end{tabular}

\section{Analisis Data Hasil Validasi Ahli Alat}

\begin{tabular}{|l|c|c|}
\hline \multicolumn{1}{|c|}{ Kriteria } & Frekuensi & Persentase \\
\hline Sangat setuju & 3 & $60.00 \%$ \\
\hline Setuju & 2 & $40.00 \%$ \\
\hline Ragu-ragu & 0 & $0.00 \%$ \\
\hline Tidak setuju & 0 & $0.00 \%$ \\
\hline Sangat tidak setuju & 0 & $0.00 \%$ \\
\hline Jumlah & 5 & $100 \%$ \\
\hline
\end{tabular}

Analisis Data Hasil Validasi Ahli Atletik I dan II

\begin{tabular}{|l|c|c|c|c|}
\hline \multirow{2}{*}{\multicolumn{1}{|c|}{ Criteria }} & \multicolumn{2}{c|}{ Frekuensi } & \multicolumn{2}{c|}{ Persentase } \\
\cline { 2 - 5 } & Ahli I & Ahli II & Ahli I & Ahli II \\
\hline Sangat setuju & 8 & 8 & $80.00 \%$ & $80.00 \%$ \\
\hline Setuju & 2 & 2 & $20.00 \%$ & $20.00 \%$ \\
\hline Ragu-ragu & 0 & 0 & $0.00 \%$ & $0.00 \%$ \\
\hline Tidak setuju & 0 & 0 & $0.00 \%$ & $0.00 \%$ \\
\hline Sangat tidak setuju & 0 & 0 & $0.00 \%$ & $0.00 \%$ \\
\hline Jumlah & 10 & 10 & $100 \%$ & $100 \%$ \\
\hline
\end{tabular}

Analisis Data Uji Coba Kelompok Kecil

\begin{tabular}{|l|l|l|l|l|}
\hline NO & Pertanyaan & Jumlah skor & Rata-rata & Persentase \\
\hline 1 & Alat ini menyenangkan & 40 & 4 & $80.00 \%$ \\
\hline 2 & Alat mudah digunakan & 40 & 4 & $80.00 \%$ \\
\hline 3 & Bentuk alat bagus & 30 & 3 & $60.00 \%$ \\
\hline
\end{tabular}




\begin{tabular}{|l|l|l|l|l|}
\hline 4 & $\begin{array}{l}\text { Alat tahan pakai dan tidak } \\
\text { roboh ketika terkena peluru }\end{array}$ & 46 & $92,00 \%$ \\
\hline 5 & $\begin{array}{l}\text { Menggunakan alat ini disetiap } \\
\text { pembelajaran tolak peluru }\end{array}$ & 43 & 4,3 & $86.00 \%$ \\
\hline
\end{tabular}

Analisis Data Uji Coba Kelompok Besar

\begin{tabular}{|l|l|c|c|c|}
\hline NO & Pertanyaan & Jumlah skor & Rata-rata & Kategori \\
\hline 1 & Alat ini menyenangkan & 164 & 4.8 & $96.47 \%$ \\
\hline 2 & Alat mudah digunakan & 168 & 4.9 & $98.82 \%$ \\
\hline 3 & Bentuk alat bagus & 165 & 4.85 & $97.05 \%$ \\
\hline 4 & $\begin{array}{l}\text { Alat tahan pakai dan tidak } \\
\text { roboh ketika terkena peluruh }\end{array}$ & 164 & 4.8 & $96.47 \%$ \\
\hline 5 & $\begin{array}{l}\text { Menggunakan alat ini disetiap } \\
\text { pembelajaran tolak peluru }\end{array}$ & 162 & 4.7 & $95.29 \%$ \\
\hline
\end{tabular}

\section{PEMBAHASAN}

Berdasarkan hasil analisis data uji validasi oleh alat dapat diketahui bahwa alat/media pembelajaran tolak peluru yang sedang peneliti kembangkan termasuk dalam kotegari baik dan layak untuk diuji cobakan, begitu juga validasi oleh 2 ahli atletik menyatakan bahwa alat/media pembelajaran layak.

Berdasarkan penilaian siswa terhadap alat yang sedang peneliti kembangkan adalah dalam kategori "baik" dengan perincian sebagai berikut: pada uji coba kelompok kecil diperoleh rata-rata skor dari pernyataan alat ini menyenangkan sebesar 4.00 yang termasuk dalam kategori "Baik" rata-rata untuk kemudahan alat saat digunakan sebesar 4.00 yang termasuk dalam kategori "Baik" rata-rata untuk bentuk alat sebesar 3.00 yang termasuk dalam kategori “ Ragu-ragu" rata-rata untuk ketahanan alat saat digunakan sebesar 4.6 yang termasuk dalam kategori "Sangat setuju/sangat baik" dan untuk penggunaan alat dalam setiap pembelajaran siswa menyatakan "Sangat setuju/sangat baik" dengan rata-rata skor 4.3. selanjutnya diperoleh juga saran dari siswa dalam kelompok kecil sarannya yaitu agar warnah diperbarui dan kaleng usakan tidak mudah jatuh 
ketika peluru mengenai tiang (tidak mengenai sasaran). Dari hasil rata-rata skor setiap pernyataan terdapat 1 pernyataan yang memiliki nilai rata-rata 3 yakni dalam kategori "Ragu-ragu" maka selanjutnya peneliti memperbaiki kekurangan dari produk yang peneliti kembangkan dan saran-saran yang ada dengan bimbingan dan masukan dari ahli alat.

Setelah peneliti melakukan perbaikan maka selanjutnya peneliti melakukan uji coba pada kelompok besar untuk menilai kelayakan alat, berdasarkan penilaian siswa diperoleh rata-rata skor diatas 4 dengan persentase diatas $90.00 \%$ ini menunjukkan bahwa alat yang peneliti kembangkan siswa sangat setuju atas kehadiran alat ini dan sangat layak, penjelasan hasil perhitungan data adalah sebagai berikut: Rata-rata skor dari pernyataan alat ini menyenangkan sebesar 4.80 yang termasuk dalam kategori "Sangat baik" rata-rata untuk kemudahan alat saat digunakan sebesar 4.90 yang termasuk dalam kategori "Sangat baik" rata-rata untuk bentuk alat sebesar 4.85 yang termasuk dalam kategori "Sangat baik" rata-rata untuk ketahanan alat saat digunakan sebesar 4.80 yang termasuk dalam kategori "Sangat setuju/sangat baik" dan untuk penggunaan alat dalam setiap pembelajaran siswa menyatakan "Sangat setuju/sangat baik" dengan rata-rata skor 4.70 .

\section{KESIMPULAN}

Hasil penelitian ini adalah sebuah produk alat pembelajaran target ring, yaitu sesuatu alat yang digunakan untuk membuat pembelajaran pendidikan jasmani cabang olahrahga atletik nomor tolak peluru. Produk yang dihasilkan dalam penelitian ini, memiliki kualitas yang sangat baik, karena pembuatannya melalui beberapa tahap, diantaranya yaitu uji validasi oleh ahli atletik, validasi oleh 2 orang ahli atletik, dan uji coba kelompok kecil dan besar oleh siswa SMPN 1 Negeri Sei Balai.

Berdasarkan hasil validasi oleh ahli alat, diperoleh hasil bahwa alat yang dikembangkan termasuk dalam kategori yang sangat baik dengan rata-rata skor 4.80. Hasil validasi oleh 2 ahli Atletik diperoleh hasil yang sama dari masingmasing ahli yakni 4.6 termasuk kategori sangat baik. 


\section{DAFTAR PUSTAKA}

Arsyad, Azhar. (2009). Media Pembelajaran, Jakarta, PT Raja Grafindo Persada brainly.co.id /tugas/3931218

Sadiman.(2009). Media Pendidikan, Pengertian, Pengembbangan dan Pemanfaatannya, Jakarta, PT Raja Grafindo Persada.

Sardiman.(2006). Interaksi dan Motivasi Belajar Mengajar, Jakarta, PT Raja Grafindo Persada.

Slameto, (2010). Belajar \& Faktor-faktor Yang Mempengaruhi, Rineka Cipta.

Soenardi, Soemosasmito. (1988) Dasar, Proses dan Efektivitas Belajar Mengajar Pendidikan Jasmani, Jakarta, P2LPTK.

Sudjana, Nana. (2009). Penilaian Hasil Proses Belajar Mengajar, Bandung, PT Remaja Rosda Karya Offset.

Sugiyono, (2016). Metode Penelitian Kuantitatif, Kualitatif, dan R\&D, Bandung, Alfabeta.

Trisna Rahayu, Ega. (2013). Strategi Pembelajaran Pendidikan Jasmani, Bandung, Alfabeta.

http://olahraga.smansax1-edu.com/2015/03/teknik-dasar-tolak-peluru-yangbenar.html

http://pustakamateri.web.id/olahraga-atletik-nomor-lempartolak/teknik-tolakpeluru

http://www.academia.edu/21642013/Keutamaan_variasi_dalam_kegiatan_belajar dan_pembela jaran.

http://www.kesekolah.com/artikel-dan-berita/olahraga/sejarah-singkat-olahragatolak-peluru.html 